\title{
Is This All?
}

\author{
Marvin L. Birnbaum, MD, PhD
}

\begin{abstract}
Meeting - an assembly of people, esp. the members of a society, committee, etc. for discussion or entertainment. ${ }^{1}$

Assembly - a group of persons gathered together, esp. as a deliberative body or a legislative council. ${ }^{2}$

Congress - a formal meeting of delegates for discussion. ${ }^{3}$

Conference-consultation, discussion; meeting for discussion. ${ }^{4}$

Forum - a place or meeting for public discussion. ${ }^{5}$
\end{abstract}

We all attend professional meetings, conferences, assemblies, conference, and/or congresses, and pay money and often travel long distances to do so. We are not forced to go; we willingly attend. We find the necessary resources and leave our jobs to attend these gatherings of our peers and super-peers. We travel, register, attend some of the sessions (we can't get to all of them), possibly present our research, use our expertise to teach others, play some in the evenings, and then, return home.

On return to our home base, how many times have we asked ourselves, "So what?"; or, "What did we really learn or gain?" We may have completed the evaluation form to be used in the development of future events. Honest evaluation always should relate to our goals and objectives or those of the meeting/event. Without clearly defined goals and objectives, it is not possible to evaluate what actually was attained. Did the conference really meet your expectations? Was it worth it?

The decision to attend a specific professional event rather than the competing ones is based on any number of possible reasons including: 1) the appeal of the venue; 2 ) the price; 3) being an invited participant; 4) the opportunity to network with your professional peers and friends; 5) professional career enhancement (presentation of a research paper; sharing your expertise by teaching others); 6) the ability to increase your knowledge in the field; 7) the results of the event may advance your science, answer some questions, resolve some issues or dilemmas, and/or establish some guidelines or standards; 8) obtain feedback for the further development of your paper; 9) etc.

Unfortunately, the scope and breadth of most conferences make it difficult to take in all parts of the program. And, while abstracts and, occasionally, synopses of some presentations are provided in a program book, what are not included are the all-important discussions that follow (or, at least, should follow) each of the presentations. These discussions are led or even provoked by the chairs (moderators), and contributions often are provided by the participants (for better understanding or to provide suggestions to the presenter), and/or the comments made by the members of panels of experts. Typically, these discussions are as important as are the contents of the papers presented.

The Supplements to this issue of PDM contain the peer-reviewed abstracts accepted for presentation by the Scientific Committees of two major scientific meetings; they have been published herein to be available to you for reference when specific questions arise. Also, perusing them may give you an overview as to what is happening in your corner of the profession - or you may be able to identify those abstracts that appeal to your particular interest by scanning the Tables of Content.

With all of this available, something still is missing. No matter what I might have gained, I still leave feeling a little empty. "What went on in the sessions that I was unable to attend?" "Perhaps, I can get it from the abstracts?" "Why did they have so many tracks?" Somehow, I have difficulty getting closure. After all, a host of my peers and superpeers were in one place at one time! How often does that happen? And, So What? Did the sessions contribute as much to our science as could have been possible given such a gathering? Was a maximum benefit obtained compared to what could have been accomplished for the cost?

These gatherings lack the structure that could optimize the value that could be obtained. There has been little variation in the structure of such meetings over the last 40 years (my direct experience). We are stuck! Same old, same old.

One unique model developed for the 5th Asia-Pacific Conference on Disaster Medicine (5APCDM) bears discussion. The organizers of this Conference decided that they wanted a palpable output that would identify the state-ofthe-art, and also, would raise important issues and questions, and could propose possible ways of gaining answers to these questions and resolutions to some of the issues (see pages s1$s 35$ in this issue). To attain these goals, the papers were organized into special topics and the chairs of each of the sessions were required to summarize the entire sessions for which they were responsible, and moreover, to develop action plans derived from the presentations AND the subsequent discussions - all related to the defined objectives for the sessions. Since the chairs were selected for their expertise in the topic, they also were able to put the proceedings into a context relative to the state of the art of their specialty. Then, these summaries and projections were presented by the chairs and 
discussed during a plenary session convened on the last day of the Conference. The final product was published in PDM (2001;16(1):18-49). Using these summaries, it is easy to understand the content and the implications of what had transpired during the entire Conference, not just those sessions I was able to attend. Furthermore, specific gaps in our science were identified, and action plans were presented that suggested how some of these gaps could be filled.

I believe it is time that we change the structure and the products of these events to increase their value. As noted, chairs/moderators are recognized experts. But, they have not participated either in the development of the objectives or in the selection of the papers to be presented in the session for which they are responsible. Rarely, have the chairs been charged with developing a summary of the proceedings in the context of the overall contributions and the meanings and implications of what had transpired. Isn't this a waste of their expertise? The participants (attendees) have paid the expenses of these important persons. Have they really obtained the full benefit of the chairs' expertise?

We must use the abilities of the experts beyond the discussions that follow most presentations. The Conference/ Congress organizers and the Scientific Committees that establish the programmes for these gatherings of fellow professionals need to develop very clear objectives as the programmes evolve. These objectives must be published in the call for abstracts so that potential contributors can identify whether their specific papers will fit within the topic areas and will contribute to the overall goals of the Congress. Furthermore, once the Scientific Committees have identified issues and gaps in knowledge that should be addressed, appropriate chairs need to be identified who are willing to work with the Organizing Committee on the development of the specific sessions (plenary, free papers, both oral and posters) that they agree to moderate. These chairs then, must develop the specific topics, identify appropriate speakers, and choose those papers to be presented that are most likely to meet these objectives. The chairs should contact each of the presenting authors to gain a better understanding of their respective presentation. This is necessary to be able to develop objectives for the entire session that should be presented as a preamble for every session. Therefore, every abstract submitted, including those for each of the plenary sessions, must have as a preamble, the objectives and goals of the presentation. Publication of such goals should help me decide which ones to lend my participation.

The moderators/chairs of each of the sessions not only are in charge, but are responsible for the content and output, and must summarize what has transpired for all of us to share. This is necessary for our science to progress in an optimal fashion. Such summaries should become the heart of the conference; they should become an essential part of the output. And, because they will be published, they will affect the development of our science, and become available to all interested, whether or not we were able to attend the specific session or even the event. We need the experts to interpret the significance of the contributions and place them into the appropriate context. The organizers must provide the support the chairs need to accomplish this task. As attendees, we deserve at least this much for what we have paid.

Just a brief word about oral presentations versus posters. Many believe posters are selected because they are not at the same level as are the papers selected for oral presentations. Actually, posters should be selected because they are important enough for everybody to peruse. It is possible for everyone to attend the poster sessions, and consequently, the more important papers should be selected for poster presentations as the potential exposure is greatest. Posters deserve the same scrutiny and attention and organization as do the oral presentations. Posters are not second class, but indeed have high priority when placed into the structure suggested above.

These suggested changes in the structure present a challenge for all of us whether conference organizers, presenters, or super-peers. Be aware of what you get, and be critical the next time you attend such a professional meeting. Help move our science forward. What better way is there to codify our science and make it accessible to us all? The objectives should exceed our goals. We need the help and guidance of experts, and hopefully, the participation of each of us will contribute to the growth of our science. This is why we come together often far from home. We must maximize the impact and benefits associated with such gatherings of our peers. The current structure fails to optimize the potential benefits at very high costs. The 13th World Congress for Disaster and Emergency Medicine (WCDEM) to be convened in Melbourne, Australia in May 2003, will be organized along these lines. This will be an exciting beginning. See if you feel better when you return home from the 13 th WCDEM. See you in Melbourne!

\section{References}

1. Thompson D (ed): The Concise Oxford Dictionary. Oxford: Clarendon 3. Ibid., 281. Press. 1995. P 848.

2. Ibid., 74 . 